\title{
(E)-Piplartine Isolated from Piper pseudoarboreum, a Lead Compound against Leishmaniasis
}

\author{
Juan C. Ticona ${ }^{1,2, \dagger}$, Pablo Bilbao-Ramos ${ }^{3,4, \dagger}{ }^{+}$Ninoska Flores ${ }^{2}$, M. Auxiliadora Dea-Ayuela ${ }^{3,5}$, \\ Francisco Bolás-Fernández ${ }^{3}$, Ignacio A. Jiménez ${ }^{1, * \mathbb{D}}$ and Isabel L. Bazzocchi ${ }^{1, *(D)}$ \\ 1 Instituto Universitario de Bio-Orgánica Antonio González and Departamento de Química Orgánica, \\ Universidad de La Laguna, Avenida Francisco Sánchez 2, 38206 La Laguna, Tenerife, Spain; \\ biojuancarlos@hotmail.com \\ 2 Instituto de Investigaciones Fármaco Bioquímicas, Facultad de Ciencias Farmacéuticas y Bioquímicas, \\ Universidad Mayor de San Andrés, Avenida Saavedra 2224, Miraflores, La Paz, Bolivia; \\ eflores5umsa@gmail.com \\ 3 Departamento de Parasitología, Facultad de Farmacia, Universidad Complutense de Madrid, Plaza Ramón y \\ Cajal s/n, 28040 Madrid, Spain; pablobil15@yahoo.com (P.B.-R.); mda_3000@yahoo.es (M.A.D.-A.); \\ francisb@ucm.es (F.B.-F.) \\ 4 Laboratorio de Parasitología y Entomología, Instituto Nacional de Laboratorios de Salud (INLASA), \\ Pasaje Rafael Zubieta 1889, Zona Miraflores, La Paz, Bolivia \\ 5 Departamento de Farmacia, Universidad CEU-Cardenal Herrera, Avenida Seminario s/n, 46113 Moncada, \\ Valencia, Spain \\ * Correspondence: ignadiaz@ull.edu.es (I.A.J.); ilopez@ull.edu.es (I.L.B.); Tel.: +34-922-318594 (I.A.J. \& I.L.B.) \\ + Both authors contribute equally to this paper.
}

Received: 30 July 2020; Accepted: 3 September 2020; Published: 7 September 2020

\begin{abstract}
The current therapies of leishmaniasis, the second most widespread neglected tropical disease, have limited effectiveness and toxic side effects. In this regard, natural products play an important role in overcoming the current need for new leishmanicidal agents. The present study reports a bioassay-guided fractionation of the ethanolic extract of leaves of Piper pseudoarboreum against four species of Leishmania spp. promastigote forms, which afforded six known alkamides (1-6). Their structures were established on the basis of spectroscopic and spectrometric analysis. Compounds $\mathbf{2}$ and $\mathbf{3}$ were identified as the most promising ones, displaying higher potency against Leishmania spp. promastigotes $\left(\mathrm{IC}_{50}\right.$ values ranging from 1.6 to $3.8 \mu \mathrm{M}$ ) and amastigotes of L. amazonensis ( $\mathrm{IC}_{50}$ values ranging from 8.2 to $9.1 \mu \mathrm{M}$ ) than the reference drug, miltefosine. The efficacy of (E)-piplartine (3) against L. amazonensis infection in an in vivo model for cutaneous leishmaniasis was evidenced by a significant reduction of the lesion size footpad and spleen parasite burden, similar to those of glucantime used as the reference drug. This study reinforces the therapeutic potential of $(E)$-piplartine as a promising lead compound against neglected infectious diseases caused by Leishmania parasites.
\end{abstract}

Keywords: Piper pseudoarboreum; bioassay-guided fractionation; leishmanicidal activity; alkamides; (E)-piplartine

\section{Introduction}

Leishmaniases are neglected tropical diseases caused by the infection with Leishmania parasites, and are transmitted by the bite of a sand fly belonging to the genera Lutzomyia and Phlebotomus. Leishmaniases are endemic in large areas of the tropics, subtropics, and the Mediterranean basin, and are among the major neglected tropical diseases causing morbidity worldwide. Recently, it has broken out of its traditional boundaries and has been reported in new geographic locations with atypical disease manifestations involving novel parasite variants. Cutaneous leishmaniasis (CL) 
is endemic in more than 70 countries, with an estimated annual incidence of 1.5-2 million new cases, and clinical manifestations ranging from small skin nodules to massive destruction of the mucous tissues. CL is mainly caused by Leishmania major in the Old World and by L. amazonensis and L. braziliensis in the New World, specifically in Brazil [1]. In spite of the high prevalence, and advances in the chemotherapy for leishmaniasis, the current available drugs, including pentavalent antimonials, amphotericin B, miltefosine, paromomycin, and pentamidine are compromised by the emergence of resistance, variable sensitivity between species, adverse side effects, requirements for long courses of administration, and high cost [2]. These drawbacks and the absence of vaccines underline the urgent need for searching alternative treatments with acceptable efficacy and safety profile.

Natural products are an important source of leishmanicidal drugs owing to their accessibility, structural diversity, low cost, and possible rapid biodegradation [3-5]. In South America, where resorting to medicinal plants represents a primary health care measure of the native population, several species of Piper genus are widely used as a remedy to relieve the symptoms of leishmaniasis disease. Thus, the leaves of Piper aduncum, P. loretoanum, and P. hispidum are used as poultices for healing wounds and to treat the symptoms of CL [6,7]. In addition, Piper species are used as culinary spices, and as a food preservative to control food spoilage and pathogenic microorganisms. In particular, P. nigrum (black pepper) is worldwide popular as a flavoring for food [8]. Phytochemical investigations of Piper species have reported numerous metabolites with ecological and medicinal properties, including amides, pyrones, lignanes, terpenes, and flavonoids [8]. Alkamides, also named piperamides, are characteristic bioactive constituents in Piper species [9]. In particular, (E)-piplartine, also called piperlongumine, is the major natural alkaloid from P. longum and P. tuberculatum, and in vitro and in vivo studies have demonstrated its promising pharmacological properties such as antioxidant, anxiolytic, anti-atherosclerosis, antidiabetic, and antiparasitic against neglected tropical diseases [10]. Moreover, $(E)$-piplartine is reported to kill a large variety of cancer cells while remaining nontoxic to normal cells, highlighting its therapeutic potential [11,12].

In previous investigations, we reported the isolation of an unprecedented chlorine-containing piperamide along with several known compounds and their antileihmanicidal activity from Piper pseudoarboreum [13]. In continuous research toward the discovery of natural occurring leihmanicidal agents, we report herein on the isolation and structure elucidation of six known alkamides from the leaves of P. pseudoarboreum Yunker through a bioassay-guided fractionation carried out against four promastigote strains of Leishmania. Compounds $\mathbf{2}$ and $\mathbf{3}$ were further evaluated on intracellular amastigotes of L amazonensis and L. infantum. (E)-piplartine (3) was selected to be assayed in an in vivo model for cutaneous leishmaniasis.

\section{Materials and Methods}

\subsection{General Experimental Procedures}

The structure of the isolated compounds were elucidated using spectrometric and spectroscopic methods, and comparison with data previously reported. The Nuclear Magnetic Resonance (NMR) experiments were recorded on Bruker Avance 400 and 500 spectrometers (Bruker Co. Billerica, MA, USA); chemical shifts were referred to the residual solvent signal $\left(\mathrm{CDCl}_{3}: \delta_{\mathrm{H}} 7.26, \delta_{\mathrm{C}} 77.36\right)$ (acetone $d_{6}$ : $\delta_{\mathrm{H}} 2.09, \delta_{\mathrm{C}} 30.60$ and 205.87), using trimethylsilane (TMS) as internal standard. Electron Impact Mass Spectrometry (EIMS) and High Resolution Electron Impact Mass Spectrometry (HREIMS) were recorded on a Micromass Autospec spectrometer (Micromass, Manchester, UK). Silica gel 60 (15-40 mm) and silica gel 60 F254 for column chromatography and Thin Layer Chromatography (TLC), respectively, were purchased from Panreac (Barcelona, Spain). Sephadex LH-20 was obtained from Pharmacia Biotech (Pharmacia, Uppsala, Sweden). Centrifugal planar chromatography was carried out in a Chromatotron instrument (model 7924T, Harrison Research Inc., Palo Alto, CA, USA) on manually coated silica gel $60 \mathrm{GF}_{254}$ (Merck, Darmstadt, Germany) using 4-mm plates. The spots were visualized by UV light and heating silica gel plates sprayed with $\mathrm{H}_{2} \mathrm{O}-\mathrm{H}_{2} \mathrm{SO}_{4}-\mathrm{AcOH}$ (1:4:20). 


\subsection{Chemicals and Reagents}

All solvents used were of analytical grade and purchased from Panreac (Barcelona, Spain). (E)-Piplartine, Scheneider's insect medium, RPMI-1640, fetal bovine serum (FBS), 4-(2-hydroxyethyl)1-piperazineethanesulfonic acid (HEPES), resazurin sodium salt, and sodium dodecyl sulphate (Sigma-Aldrich, St Louis, MO, USA), L-glutamine (Avantor Performance Material Inc., PA, USA), trypsin (Merck, Darmstadt, Germany), penicillin Penilevel ${ }^{\circledR} 100.000$ U.I. (ERN laboratories, Barcelona, Spain), streptomycin sulphate (Reig Jofré laboratories, Barcelona, Spain), and Glucantime ${ }^{\circledR}$ (Merial Laboratories, Barcelona, Spain).

\subsection{Plant Material}

Leaves of Piper pseudoarboreum Yunck. were collected in November 2009 at Iquitos, Maynas Province, Department of Loreto, Perú. The plant material was identified by the botanist Juan Celedonio Ruiz Macedo, and a voucher specimen (AMZ 11114) was deposited at the Amazonense Herbarium of the Universidad Nacional de la Amazonia Peruana, Iquitos, Perú.

\subsection{Extraction, Bioassay-Guided Fractionation and Isolation}

The dried leaves of P. pseudoarboreum (200.3 g) were powdered and extracted in a Soxhlet apparatus with $5 \mathrm{~L}$ of $96 \%$ ethanol. The solvent was evaporated to give $42.9 \mathrm{~g}(21.4 \%)$ of extract. The ethanolic extract $(\mathrm{EtOH})$ was partitioned into dichlorometane (DCM), ethyl acetate $(\mathrm{EtOAc})$, and water $\left(\mathrm{H}_{2} \mathrm{O}\right)$. After removing the organic solvents under reduced pressure, the DCM $(9.2 \mathrm{~g}, 4.6 \%)$ and EtOAc $(1.2 \mathrm{~g}$, $0.6 \%$ ) fractions were obtained, whereas the aqueous-soluble extract was lyophilized providing the $\mathrm{H}_{2} \mathrm{O}$ fraction ( $8.9 \mathrm{~g}, 4.5 \%$ ). The most active organic fraction (DCM, $9.2 \mathrm{~g}$ ) was chromatographed over silica gel column eluting with mixtures of hexanes-EtOAc (10:0 to 0:10, $1 \mathrm{~L}$ each one) to obtain seven sub-fractions (F1-F7). The most active fraction, F6 (1.5 g), was subjected to column chromatography over Sephadex $\mathrm{LH}-20$ by isocratic elution ( $\left.\mathrm{MeOH}-\mathrm{CHCl}_{3}, 1: 1\right)$ to afford fifteen sub-fractions, which were combined based on their TLC profiles (F6A to F6F). Preliminary nuclear magnetic resonance (NMR) studies revealed that sub-fraction F6B was rich in aromatic alkamides, and were further investigated. Thus, F6B (448.1 mg) was chromatographed by centrifugal planar chromatography on 4-mm silica gel plates, using mixtures of hexanes-EtOAc (60:40 to 50:40) as eluent to give eleven sub-fractions (F6B1 to F6B11). Sub-fraction F6B2 $(21.5 \mathrm{mg})$ was further purified on silica gel by preparative TLC ( $3 \times$ development, hexanes-2-propanol, 8:2) to give compounds $\mathbf{1}(1.7 \mathrm{mg})$ and $\mathbf{5}(1.4 \mathrm{mg})$. Purification of sub-fraction F6B4 $(18.3 \mathrm{mg})$ by preparative TLC $\left(2 \times\right.$ development, $\left.\mathrm{CH}_{2} \mathrm{Cl}_{2}-\mathrm{Et}_{2} \mathrm{O}, 95: 5\right)$ yielded compounds $3(11.4 \mathrm{mg})$ and $4(2.2 \mathrm{mg})$, whereas sub-fraction F6B7 $(23.8 \mathrm{mg})$ gave compounds 2 $(19.8 \mathrm{mg})$ and $6(0.9 \mathrm{mg})$ after purification by preparative TLC $(2 \times$ development, hexanes-2-propanol, 8:2). The compounds were identified by NMR spectroscopy and comparison with data reported in the literature.

\subsection{Biological Studies}

\subsubsection{Parasites}

Autochthonous isolates of Leishmania infantum (MCAN/ES/92/BCN83) were obtained from an asymptomatic dog from the Priorat region (Catalunya, Spain), and kindly provided by Prof. Montserrat Portús (University of Barcelona). L. braziliensis (2903), L. amazonensis (MHOM/Br/79/Maria) and L. guyanensis (141/93) were kindly given by Prof. Alfredo Toraño (Instituto de Salud Carlos III, Madrid).

\subsubsection{Cells}

J774 murine macrophages were grown and maintained in RPMI-1640 medium supplemented with $10 \%$ heat-inactivated FBS, penicillin $\mathrm{G}(100 \mathrm{U} / \mathrm{mL})$, and streptomycin $(100 \mu \mathrm{g} / \mathrm{mL})$ at $37^{\circ} \mathrm{C}$ and $5 \%$ $\mathrm{CO}_{2}$ air atmosphere. 


\subsubsection{Animals}

Male BALB/c mice of 20-25 g body weigh were purchased from Harlan Interfauna Ibérica (Barcelona, Spain). All rodents were housed in plastic cages in a $12 \mathrm{~h}$ dark-light cycle under controlled temperature $\left(25^{\circ} \mathrm{C}\right)$ and humidity $(70 \%)$ conditions. During the study, animals had unrestricted access to food and water.

\subsubsection{In Vitro Promastigotes Susceptibility Assay}

In vitro antileishmanial assay was performed using a method described elsewhere [14]. Briefly, promastigotes were grown in vitro in a Schneider's insect medium supplemented with $20 \%$ heat-inactivated FBS, penicillin $(100 \mathrm{U} / \mathrm{mL})$ and streptomycin $(100 \mu \mathrm{g} / \mathrm{mL})$ at $26^{\circ} \mathrm{C}$ in $25 \mathrm{~mL}$ in tissue culture flasks, and were cultured in 96 -well plastic plates $\left(2.5 \times 10^{5}\right.$ parasites/well). Compounds dissolved in dimethylsulfoxide $1 \%$ (DMSO) at the suitable concentration to be tested in serial dilutions (a first screening using $100 \mu \mathrm{g} / \mathrm{mL}$, and then $100,50,25,12.5,6.25,3.12,1.56$ and $0.78 \mu \mathrm{g} / \mathrm{mL}$ ) to get a final volume of $200 \mu \mathrm{L}$ were added to each well. After an incubation of $48 \mathrm{~h}$ at $26^{\circ} \mathrm{C}, 20 \mu \mathrm{L}$ of $2.5 \mathrm{mM}$ resazurin solution was added. Plates were then analyzed by fluorescence emission $\left(535_{\mathrm{ex}}-590_{\mathrm{em}} \mathrm{nm}\right)$ using a fluorometer Infinite 200 (Tecan i-Control, Tecan Group Ltd, Männedorf, Switzerland). All tests were carried out in triplicate, and miltefosine was used as the reference drug. The antileishmanial activity of each compound was estimated by calculating the GI\% (percentage of growth inhibition) and then the $\mathrm{IC}_{50}$ value (concentration of the compound that produced a $50 \%$ reduction in parasites).

\subsubsection{Cytotoxicity Assay}

The cytotoxicity assay of the tested compounds was performed according to a previously described method [14]. Briefly, J774 macrophages $\left(5 \times 10^{4}\right.$ cells/well) were placed in 96-well flat-bottom plates with $100 \mu \mathrm{L}$ of RPMI-1640 medium, and allowed to attach at $37^{\circ} \mathrm{C}$ and $5 \% \mathrm{CO}_{2}$ for $2 \mathrm{~h}$. Afterwards, $100 \mu \mathrm{L}$ of RPMI-1640 medium containing the test compound in varying concentrations $(100,50,25$, $12.5,6.25,3.12,1.56$, and $0.78 \mu \mathrm{g} / \mathrm{mL}$ ) were added to the cells and incubated for another $48 \mathrm{~h}$. Growth controls and signal-to-noise were included. Following the aforementioned incubation time, $20 \mu \mathrm{L}$ of $2.5 \mathrm{mM}$ resazurin solution in PBS was added, and the plates were placed again in the incubator for another $3 \mathrm{~h}$ to evaluate cell viability. The ability of cells to reduce resazurin was determined by fluorometry as in the promastigote assay. Each concentration was assayed in triplicate. Cytotoxicity was expressed as the $50 \%$ reduction of cell viability of treated culture cells with respect to untreated culture $\left(\mathrm{CC}_{50}\right)$.

\subsubsection{In Vitro Amastigote Assay}

The effectiveness against intracellular amastigotes was evaluated using a fluorometric method described elsewhere [15]. Briefly, macrophages $\left(5 \times 10^{4}\right.$ cells) and stationary Leishmania promastigotes in a ratio of 1:10 (macrophage/parasite) were seeded in each well of a microtiter plate, suspended in $200 \mu \mathrm{L}$ of culture medium and incubated at $33^{\circ} \mathrm{C}$ and $5 \% \mathrm{CO}_{2}$ for $24 \mathrm{~h}$. After this incubation time, the temperature was increased up to $37^{\circ} \mathrm{C}$ for another $24 \mathrm{~h}$. Cells were washed with medium several times in order to remove free non-infective promastigotes, and the supernatant was replaced by $200 \mu \mathrm{L} /$ well of culture medium containing two-fold serial dilutions of the test compounds (ranging from 5 to $0.038 \mu \mathrm{g} / \mathrm{mL}$ ) and the reference drug (ranging from 50 to $0.38 \mu \mathrm{g} / \mathrm{mL}$ ). The culture medium was removed carefully to be replaced by $200 \mu \mathrm{L} /$ well of the lysis solution (RPMI-1640 with $0.048 \%$ HEPES and $0.006 \%$ sodium dodecyl sulfate (SDS)) and incubated at room temperature for $20 \mathrm{~min}$. Thereafter, the plates were centrifuged at $3500 \times g$ for $5 \mathrm{~min}$ and the lysis solution was replaced by $200 \mu \mathrm{L} /$ well of Schneider's insect medium. The culture plates were incubated at $26^{\circ} \mathrm{C}$ for another 3 days for the transformation of viable promastigotes into amastigotes. Afterwards, $20 \mu \mathrm{L} /$ well of $2.5 \mathrm{mM}$ resazurin was added and incubated for $3 \mathrm{~h}$. Plates were analyzed by fluorescence emission, 
and $\mathrm{IC}_{50}$ was determined as described above. All tests were carried out in triplicate. Miltefosine was used as reference drug and was evaluated at the same conditions.

\subsubsection{In Vivo Experiments}

BALB/c mice were infected subcutaneously at the left hand-foot with $1 \times 10^{7}$ promastigotes of L. amazonensis on day 0. Right hind paw was used as a negative control (no infection). Thirty five days after infection, chronic cutaneous leishmaniasis was developed, and animals were randomly divided into three groups ( $n=8 /$ group): animals treated with $(E)$-piplartine received in the foot lesions (intralesion) doses of $25 \mathrm{mg} / \mathrm{kg} /$ day for 4 days in a $15 \mu \mathrm{L}$ volume of phosphate saline dilution/propylene glycol (9:1), a group treated with glucantime receiving $25 \mathrm{mg} / \mathrm{kg} /$ day for 4 days by intraperitoneal route, and the control group. The measurement of cutaneous lesion was monitored at $0,35,50$, and 100 days post-infection, using a Vernier calliper to measure footpad size. The number of viable L. amazonensis parasites in the spleen of the different groups of mice was estimated using the limiting dilution assay method at the end of the experiment (day 100 post-infection) [16]. Mice were sacrificed, and the spleen were aseptically removed, weighed, and homogenized in Schneider's medium supplemented with $10 \%$ FBS. Briefly, serial dilutions were prepared and distributed to 96-well microtiter plates under sterile conditions, and incubated at $26^{\circ} \mathrm{C}$. On day 7 post-incubation, wells were analyzed using an inverted microscope. The number of parasites per milligram of tissue was determined based on the tissue weight and the parasite load from the culture dilutions [17].

\subsubsection{Ethical Consideration}

All animals were handled according to the European Union legislation Directive 2010/63/EU and Spanish law Real Decreto 53/2013 on the protection of animals used for scientific purposes. The experimental protocols involving the use of animals were approved by the local ethical committee of the University Complutense of Madrid (CEXAN170415) http:/147.96.70.122/Web/Actas/CEXAN170415.pdf.

\subsubsection{Statistical Analysis}

For in vitro assays, the antileishmanial activity $\left(\mathrm{IC}_{50}\right)$ and cytotoxic activity $\left(\mathrm{CC}_{50}\right)$ of compounds were analyzed by Probit test, using SPSS v20.0 software. All results were expressed as means \pm standard error of the mean (S.E.M). For in vivo assays, results were analyzed by Shapiro-Wilk's normality test, and then by one-way ANOVA with Tukey's HSD post-hoc test. Significant differences were considered at $p$-value $<0.05$, using SPSS v20.0 and Microsoft Excel 2010 software.

\section{Results and Discussion}

The ethanolic extract of the leaves of $P$. pseudoarboreum was evaluated against promastigote forms of L. amazonensis, L. braziliensis, L. guyanensis, and L. infantum. The active EtOH crude extract was further fractionated by liquid-liquid partition to obtain DCM, EtOAc, and $\mathrm{H}_{2} \mathrm{O}$ fractions, which were assayed for their in vitro activity against the four Leishmania strains.

The DCM fraction showed an improved profile compared to the crude extract, displaying $\mathrm{IC}_{50}$ values ranging from 14.7 to $19.1 \mu \mathrm{g} / \mathrm{mL}$ for the four Leishmania strains assayed, whereas the EtOAc and $\mathrm{H}_{2} \mathrm{O}$ fractions showed to be inactive $\left(\mathrm{IC}_{50}>50 \mu \mathrm{g} / \mathrm{mL}\right.$ ). Thus, $\mathrm{DCM}$ fraction was further fractionated to yield seven sub-fractions. Sub-fractions F1-F4 showed to be inactive $\left(\mathrm{IC}_{50}>100 \mu \mathrm{M}\right)$, whereas sub-fraction F5 showed some degree of activity on the four Leishmania strains ( IC $_{50} 15.7-20.8 \mu \mathrm{g} / \mathrm{mL}$ ) and F7 exhibited only slight potency on L. amazonensis and L. brazilensis. Moreover, the most active sub-fraction $\mathrm{F} 6$ exhibited higher potency than miltefosine, used as the reference drug $\left(\mathrm{IC}_{50}\right.$ ranging from 2.2 to $3.4 \mu \mathrm{M}$ vs. 17.7 to $30.7 \mu \mathrm{M}$ ), although showed a slightly low selectivity index taking J774 macrophages as reference mammalian cells ( $\mathrm{CC}_{50}$ values ranging from 1.9 to $3.0 \mathrm{vs.} 4.4$ to 7.7$)$ (Table 1 ). 
Table 1. Leishmanicidal activity on promastigotes forms and cytotoxic activity on macrophages of the extract, fractions, sub-fractions, and isolated compounds ${ }^{a}$ from P. pseudoarboreum.

\begin{tabular}{|c|c|c|c|c|c|c|c|c|c|}
\hline \multirow{2}{*}{ Sample } & \multicolumn{2}{|c|}{ L. amazonensis } & \multicolumn{2}{|c|}{ L. braziliensis } & \multicolumn{2}{|c|}{ L. guyanensis } & \multicolumn{2}{|c|}{ L. infantum } & \multirow{2}{*}{$\begin{array}{c}\mathrm{J} 774 \\
\mathrm{CC}_{50}{ }^{c} \pm \mathrm{SD}\end{array}$} \\
\hline & $\mathrm{IC}_{50}{ }^{b} \pm \mathrm{SD}$ & $\mathrm{SI}^{d}$ & $\mathrm{IC}_{50}{ }^{b} \pm \mathrm{SD}$ & $\mathrm{SI}^{d}$ & $\mathrm{IC}_{50}^{b} \pm \mathrm{SD}$ & $\mathrm{SI}^{d}$ & $\mathrm{IC}_{50}^{b} \pm \mathrm{SD}$ & $\mathrm{SI}^{d}$ & \\
\hline EtOH & $31.4 \pm 2.5$ & 1.8 & $21.3 \pm 1.0$ & 2.6 & $41.3 \pm 1.4$ & 1.3 & $32.3 \pm 1.4$ & 1.7 & $55.0 \pm 4.1$ \\
\hline DCM & $17.7 \pm 0.3$ & 1.9 & $14.7 \pm 0.8$ & 2.3 & $19.1 \pm 0.2$ & 1.8 & $18.4 \pm 0.3$ & 1.9 & $34.1 \pm 3.4$ \\
\hline F5 & $18.5 \pm 0.1$ & 1.2 & $15.7 \pm 2.8$ & 1.4 & $20.8 \pm 0.8$ & 1.1 & $20.3 \pm 0.3$ & 1.1 & $22.6 \pm 2.2$ \\
\hline F6 & $2.5 \pm 0.0$ & 2.6 & $2.2 \pm 0.1$ & 3.0 & $3.4 \pm 0.2$ & 1.9 & $3.0 \pm 0.1$ & 2.2 & $6.5 \pm 1.3$ \\
\hline F7 & $40.0 \pm 1.1$ & 0.8 & $46.7 \pm 5.1$ & 0.7 & - & - & - & - & $30.8 \pm 2.8$ \\
\hline 1 & $28.0 \pm 1.0$ & 0.8 & $28.7 \pm 1.0$ & 0.8 & $24.6 \pm 0.0$ & 0.9 & $27.7 \pm 1.7$ & 0.8 & $23.2 \pm 3.1$ \\
\hline 2 & $1.7 \pm 0.3$ & 6.6 & $1.7 \pm 0.0$ & 6.6 & $2.1 \pm 0.0$ & 5.5 & $3.8 \pm 0.3$ & 3.0 & $11.5 \pm 0.7$ \\
\hline 3 & $2.2 \pm 0.0$ & 4.7 & $1.6 \pm 0.3$ & 6.6 & $2.2 \pm 0.3$ & 4.7 & $2.2 \pm 1.6$ & 4.7 & $10.4 \pm 0.9$ \\
\hline 4 & $3.5 \pm 0.0$ & 3.6 & $2.5 \pm 0.0$ & 5.0 & $3.8 \pm 0.0$ & 3.3 & $5.4 \pm 0.3$ & 2.4 & $12.6 \pm 3.8$ \\
\hline 5 & - & - & - & - & $88.0 \pm 2.4$ & 0.6 & - & - & $52.2 \pm 23.0$ \\
\hline $\mathbf{M}^{e}$ & $30.7 \pm 0.9$ & 4.4 & $17.7 \pm 0.4$ & 7.7 & $19.4 \pm 1.2$ & 7.0 & $17.7 \pm 1.8$ & 7.7 & $135.9 \pm 10.3$ \\
\hline
\end{tabular}

${ }^{a}$ Fractions and compounds not included in the table were inactive $\left(\mathrm{IC}_{50}>50 \mu \mathrm{g} / \mathrm{mL}\right.$ and $\mathrm{IC}_{50}>100 \mu \mathrm{M}$, respectively). ${ }^{b} \mathrm{IC}_{50}$ : concentration able to inhibit $50 \%$ of parasites. The $\mathrm{IC}_{50}$ values of the ethanol extract $(\mathrm{EtOH})$ and dichloromethane (DCM) and F5-F7 fractions are expressed as $\mu \mathrm{g} / \mathrm{mL} \pm$ standard deviation. The $\mathrm{IC}_{50}$ values of the compounds are expressed as $\mu \mathrm{M} \pm$ standard deviation. ${ }^{c} \mathrm{CC}_{50}$ concentration able to inhibit $50 \%$ of murine macrophages. ${ }^{d}$ SI: selectivity index $\left(\mathrm{CC}_{50} / \mathrm{IC}_{50}\right) .{ }^{e} \mathrm{M}$ : miltefosine was used as a positive control.

Therefore, sub-fraction F6 was submitted to multiple chromatographic steps on silica gel and Sephadex LH-20 affording the known alkamides 1-6 (Figure 1). Their chemical structures were elucidated on the basis of their spectroscopic data (Supplementary Materials Figures S1-S6) and comparison with data reported in the literature. Thus, the isolated metabolites were identified as sintenpyridone (1) [18], (E)-demethoxypiplartine (2) [19], (E)-piplartine (also known as piperlongumine, 3) [19], (Z)-piplartine (4) [20], 3,4-epoxy-8,9-dihydropiplartine (5) [21], and 10,11-dihydropiperine (6) [20].
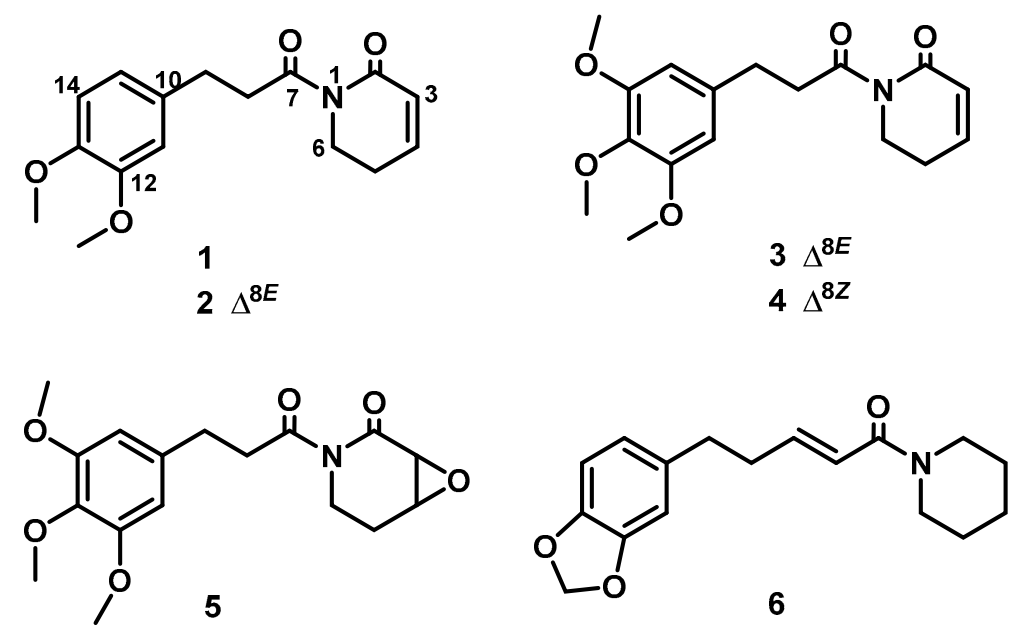

Figure 1. Chemical structures of piperamides (1-6) isolated from Piper pseudoarboreum.

Alkamides 1-6 were tested by in vitro assays against the four strains of Leishmania promastigotes. The results indicated that alkamides 2 and 3 were 4.7 to 18 -fold more potent $\left(\mathrm{IC}_{50}\right.$ ranging from 1.6 to $3.8 \mu \mathrm{M}$ ) than miltefosine ( $\mathrm{IC}_{50}$ ranging from 17.7 to $30.7 \mu \mathrm{M}$ ), and exhibited a selectivity index ranging from 3.0 to 6.6 for all Leishmania strains tested (Table 1). Recently, Araújo-Vilges and co-workers reported that (E)-piplartine was able to reduce the growth of L. amazonensis promastigotes (MHOM/BR/pH8) in a dose-dependent pattern, exhibiting an $\mathrm{IC}_{50}$ value of $179.0 \mu \mathrm{g} / \mathrm{mL}$ [22]. On the other hand, Capello et al. [23] reported that no antileishmanial activity on macrophages infected with L. (L.) amazonensis was found for (E)-piplartine at $50 \mu \mathrm{g} / \mathrm{mL}$. We assume that such differences in potency depend to a great extent on the infecting Leishmania strain used in the assay and cell culture procedures.

Regarding the influence of the substitution pattern in the alkamide scaffold on the leishmanicidal activity, it seems that $\alpha, \beta$-unsaturated carbonyl groups in both, the acyl chain and the lactam ring 
are critical functionalities for the activity $(2,3$, and 4 vs. 1, 5, and 6). Moreover, isomerization of the unsaturated acyl chain leads to slight changes in the activity (3 vs. 4). No straightforward conclusion can be drawn from the type of functional group on the aromatic ring.

Based on the in vitro results on promastigote forms, alkamides 2 and 3 were selected to be evaluated on intracellular amastigotes of L. amazonensis and L. infantum. The results revealed that compounds 2 and 3 exhibited some degree of activity, showing two-fold higher potency on L. amazonesis ( $\mathrm{IC}_{50} 9.1$ and $8.2 \mu \mathrm{M}$, respectively) than on L. infantum ( $\mathrm{IC}_{50} 17.1$ and $16.1 \mu \mathrm{M}$, respectively). Moreover, both compounds exhibited higher activity than miltefosine on both assayed Leishmania strains. Furthermore, these compounds were 5- to 6-fold more potent than miltefosine on L. amazonensis (Table 2).

Table 2. Leishmanicidal activity on amastigote forms of alkamides 2 and 3.

\begin{tabular}{ccccc}
\hline \multirow{2}{*}{ Compounds } & \multicolumn{2}{c}{ L. amazonesis } & \multicolumn{2}{c}{ L. infantum } \\
\cline { 2 - 5 } & $\mathbf{I C}_{\mathbf{5 0}}{ }^{\boldsymbol{a}} \pm \mathbf{S D}$ & SI $^{\boldsymbol{b}}$ & $\mathbf{I C}_{\mathbf{5 0}} \pm \mathbf{S D}$ & SI $^{\boldsymbol{b}}$ \\
\hline $\mathbf{2}$ & $9.1 \pm 0.2$ & 1.3 & $17.1 \pm 0.1$ & 0.7 \\
$\mathbf{3}$ & $8.2 \pm 0.1$ & 1.3 & $16.1 \pm 0.1$ & 0.7 \\
$\mathbf{M}^{c}$ & $49.3 \pm 0.2$ & 2.8 & $23.6 \pm 0.4$ & 5.8 \\
\hline
\end{tabular}

${ }^{a} \mathrm{IC}_{50}$ : concentrations able to inhibit $50 \%$ of the parasites, and values are expressed as $\mu \mathrm{M} \pm$ standard deviation (SD). ${ }^{b}$ SI: selectivity index $\left(\mathrm{CC}_{50}\right.$ of murine macrophages/ $\left./ \mathrm{IC}_{50}\right) .{ }^{c} \mathrm{M}$ : Miltefosine was used as a positive control.

Taking into consideration its potency and efficacy on Leishmania promastigote and amastigote forms, and although a poor selectivity index, $(E)$-piplartine was selected for in vivo assays to investigate its potential as a lead compound targeting CL since previous toxicological studies indicate a good safety profile in murine models [10]. Previous works report the in vitro evaluation of $(E)$-piplartine against Leishmania spp. promastigotes [22,24] and L. amazonensis intracellular amastigote forms [25] as well as an in vivo study against $L$. donovani in a hamster model of visceral leishmaniasis [24]. However, to our knowledge, in vivo studies on CL have not been reported.

The in vivo assay in BALB/c mice infected with L. amazonensis for $\mathrm{CL}$ was performed by treatment of three randomly separated mice groups (8 mice per group). Thirty five days after infection, the treated mice group with (E)-piplartine received in the foot lesions (intralesion) a dose of $25 \mathrm{mg} / \mathrm{kg} / \mathrm{day}$ for 4 days, whereas the treated group with glucantime received by intraperitoneal route $25 \mathrm{mg} / \mathrm{kg} / \mathrm{day}$ for 4 days. The lesion size footpad was measured four times before infection and treatment, after treatment and at the end of the experiment (days 0, 35, 50, and 100) (Figures 2 and 3). The individual lesion size was calculated from two measurements (differences between the left and the right footpad).

Moreover, with the aim to establish the visceralization of the chronic infection disease, all mice were sacrificed at the end of the experiment to determine parasite burden in spleen by culture on microtiter plates. This in vivo assay indicated that from the day of infection to the day before treatment with (E)-piplartine, the progress of the lesion size was similar in the three mice groups (day 35), whereas after the end of treatment (day 50), the mean progress of lesions within groups treated with (E)-piplartine and glucantime were reduced by around $35 \%$ with respect to the untreated group. At the end of the experiment, both treated groups showed more than $40 \%$ reduction in the lesion size and $55 \%$ in spleen parasite burden compared to untreated mice group. The intralesion (E)-piplartine treatment efficacy was comparable to the intraperitoneal glucantime treatment, with $p$-values of 0.800 and 0.832 for the lesion size and spleen parasite burden, respectively, and significantly higher than the untreated control group, with $p$-values of 0.045 and 0.027 , respectively (Table 3). 
$\mathbf{A}$

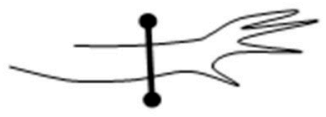

B
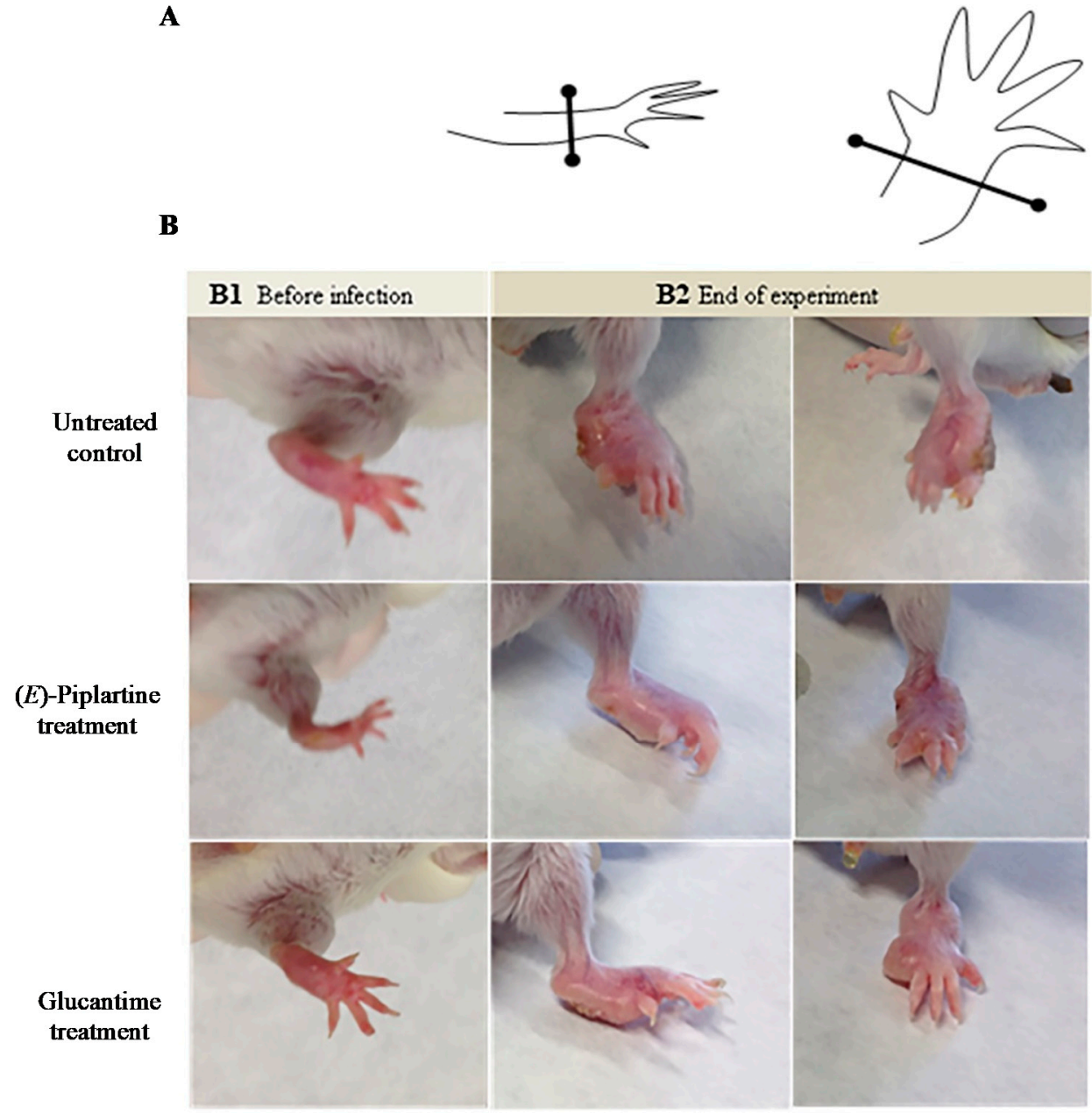

Figure 2. Effect of the treatment with (E)-piplartine on chronic cutaneous leishmaniasis in BALB/c mice. (A) Graphic representation of footpad measurement: thickness (left) and width (right). Lesion size is expressed as the difference in size between the infected and contralateral non-infected footpads. (B) Representative images of a mouse infected with Leishmania amazonensis, at day 0 (B1) and at the end of experiment (B2).

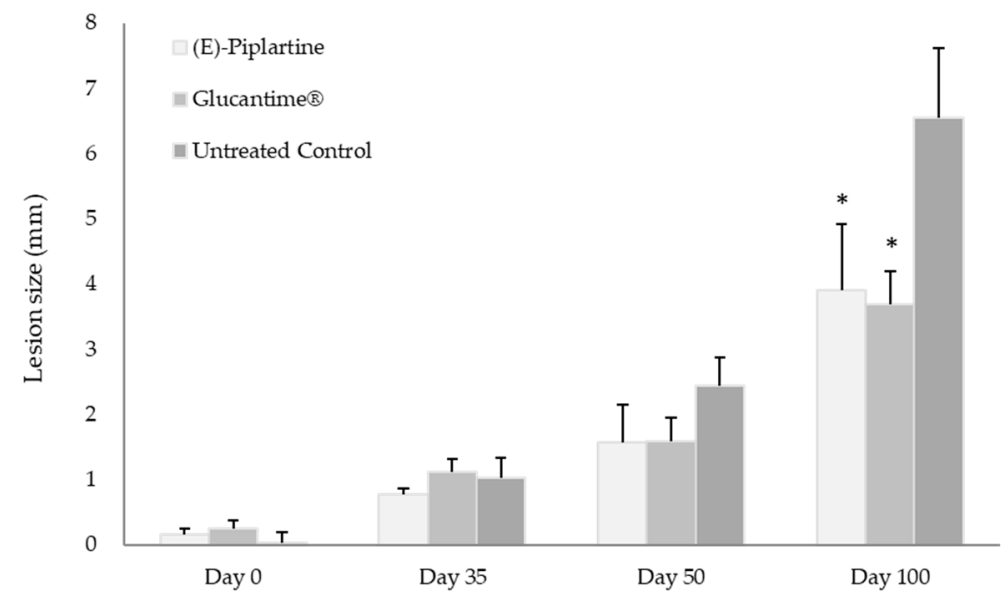

Figure 3. Effectiveness of (E)-piplartine in the treatment of chronic cutaneous leishmaniasis. Lesion size was measured four times (day 0 , day 35 , day 50 , and day 100) and expressed as a mean of the group in $\mathrm{mm}$. At end of the experiment, lesion size of (E)-piplartine vs. glucantime treated mice groups did not show statistically significant differences with $p$-value $>0.800$; untreated control group vs. (E)-piplartine and glucantime showed significant differences with $p$-value $<0.000 *$. 
Table 3. Efficacy of (E)-piplartine in the control of the visceralization in chronic Cutaneous Leishmaniasis.

\begin{tabular}{cccc}
\hline \multirow{2}{*}{ Mice Groups } & \multicolumn{3}{c}{ Spleen Parasite Burden ${ }^{a}$} \\
\cline { 2 - 4 } & Number and Percentage & SEM $^{b}$ and Percentage & $p$-Value with Untreated Control \\
\hline Untreated control & $277.17(100 \%)$ & $\pm 43.3(15.6 \%)$ & - \\
$(E)$-Piplartine treated & $122.6(44.2 \%)$ & $\pm 40.3(14.5 \%)$ & 0.045 \\
Glucantime $^{\circledR}$ treated & $111.6(40.3 \%)$ & $\pm 46.8(16.9 \%)$ & 0.027 \\
\hline
\end{tabular}

${ }^{a}$ Number of parasites per gram in spleen measured on day 100 of infection. ${ }^{b}$ SEM: Standard error of the mean.

Thus, the results indicated that (E)-piplartine was effective in the in vivo assay (Figures 2 and 3 , and Table 3) as evidenced by a significant reduction in the lesion size footpad after infection, and in the spleen parasite burden at the end of the experiment (day 100 post-infection). These findings, together with previous safety $[22,25]$ and pharmacokinetic studies $[10,26]$, provide additional experimental evidence of the potential of (E)-piplartine as a promising leishmanicidal lead compound.

In this study, the intralesional route for $(E)$-piplartine was chosen in order to develop a prospective formulation for topical administration. This administration route is an attractive alternative for CL, offering significant advantages over systemic therapy with: fewer adverse side effects, easy administration, and low costs [27]. This later point is relevant as in regions with limited resources there are no dispensaries or qualified personnel for intramuscular or intravenous drug administration [28]. In addition, topical formulations can penetrate over the skin to diminish disease progression at the beginning of the infection [29].

Although the mechanism of action of (E)-piplartine has not been established on Leishmania parasites, previous studies performed on cancer cell lines $[12,30,31]$ have demonstrated that this alkamide is able to inhibit the proliferative process by activation of mitochondrial apoptosis pathways and induction of reactive oxygen species. Considering these studies, the effect of $(E)$-piplartine on Leishmania parasites could also be related to the activation of apoptotic events. Moreover, further studies should be undertaken in order to determine the leishmanicidal mechanism of action of this promising lead compound.

\section{Conclusions}

The results reported herein reinforce the efficacy of $(E)$-piplartine against neglected tropical diseases caused by Leishmania spp., and deserve future investigations for further lead optimization with desired drug-likeness properties for the treatment of leishmaniasis. Furthermore, $(E)$-piplartine is a natural alkamide occurring in several species in the widely distributed Piper genus, and therefore, the in vivo studies results support and may validate the traditional uses of some Piper species by the indigenous people to treat the symptoms of cutaneous leishmaniasis.

Supplementary Materials: The following are available online at http://www.mdpi.com/2304-8158/9/9/1250/s1, Figures S1-S6: ${ }^{1} \mathrm{H}$ and ${ }^{13} \mathrm{C}$ NMR spectra of compounds 1-6.

Author Contributions: Conceptualization, I.A.J. and F.B.-F.; methodology, I.A.J., M.A.D.-A., and J.C.T.; investigation, J.C.T. and P.B.-R.; data curation, M.A.D.-A. and N.F.; writing-the original draft preparation; N.F. and I.A.J.; writing-reviewed and editing, I.L.B.; funding acquisition, I.L.B. and F.B.-F. All authors have read and agreed to the published version of the manuscript.

Funding: This research was funded by RTI2018-094356-B-C21 Spanish MINECO project, cofunded by the European Regional Development Fund (FEDER) and PCI-lberoamerica A/030160/10 and AP/039767/11 projects from Spanish MAEC-AECID. J.C.T. and P.B.-R. are grateful to Spanish MAEC-AECID for their fellowships.

Acknowledgments: The authors would like to thank the botanist Juan Celedonio Ruiz Macedo, Amazonense Herbarium of the Universidad Nacional de la Amazonia Peruana, Iquitos, Perú, for the identification of the plant material.

Conflicts of Interest: The authors declare no conflict of interest. 


\section{References}

1. World Health Organization, Update March 2019. Available online: http://www.who.int/news-room/factsheets/detail/leishmaniasis (accessed on 8 April 2020).

2. Passero, L.F.D.; Cruz, L.A.; Santos-Gomes, G.; Rodrigues, E.; Laurenti, M.D.; Lago, J.H.G. Conventional versus natural alternative treatments for Leishmaniasis: A Review. Curr. Top. Med. Chem. 2018, 18, 1275-1286. [CrossRef]

3. Bekhit, A.A.; El-Agroudy, E.; Helmy, A.; Ibrahim, T.M.; Shavandi, A.; Bekhit, A.E.A. Leishmania treatment and prevention: Natural and synthesized drugs. Eur. J. Med. Chem. 2018, 60, 229-244. [CrossRef] [PubMed]

4. Hussian, H.; Al-Harrasi, A.; Al-Rawahi, A.; Green, I.R.; Gibbons, S. Fruitful decade for antileishmanial compounds from 2002 to late 2011. Chem. Rev. 2014, 114, 10369-10428. [CrossRef] [PubMed]

5. Newman, D.J.; Cragg, G.M. Natural products as sources of new drugs over the nearly four decades from 01/1981 to 09/2019. J. Nat. Prod. 2020, 83, 770-803. [CrossRef] [PubMed]

6. Braga, F.G.; Bouzada, M.L.; Fabri, R.L.; de O Matos, M.; Moreira, F.O.; Scio, E.; Coimbra, E.S. Antileishmanial and antifungal activity of plants used in traditional medicine in Brazil. J. Ethnopharmacol. 2007, 111, 396-402. [CrossRef] [PubMed]

7. Odonne, G.; Bourdy, G.; Castillo, D.; Estevez, Y.; Lancha-Tangoa, A.; Alban-Castillo, J.; Deharo, E.; Rojas, R.; Stien, D.; Sauvain, M. Ta'ta', Huayani: Perception of leishmaniasis and evaluation of medicinal plants used by the Chayahuita in Peru. Part II. J. Ethnopharmacol. 2009, 126, 149-158. [CrossRef] [PubMed]

8. Salehi, B.; Zakaria, Z.A.; Gyawali, R.; Ibrahim, S.A.; Rajkovic, J.; Shinwari, Z.K.; Khan, T.; Sharifi-Rad, J.; Ozleyen, A.; Turkdonmez, E.; et al. Piper species: A comprehensive review on their phytochemistry, biological activities and applications. Molecules 2019, 24, 1364. [CrossRef]

9. Rios, M.Y.; Olivo, H.F. Natural and synthetic alkamides: Applications in pain therapy. Studies Nat. Prod. Chem. 2014, 43, 79-121.

10. Bezerra, D.P.; Pessoa, C.; de Moraes, M.O.; Saker-Neto, N.; Silveira, E.R.; Costa-Lotufo, L.V. Overview of the therapeutic potential of piplartine (piperlongumine). Eur. J. Pharm. Sci. 2013, 48, 453-463. [CrossRef]

11. Adams, D.J.; Dai, M.; Pellegrino, G.; Wagner, B.K.; Stern, A.M.; Shamji, A.F.; Schreiber, S.L. Synthesis, cellular evaluation, and mechanism of action of piperlongumine analogs. Proc. Natl. Acad. Sci. USA 2012, 109, 15115-15120. [CrossRef]

12. Li, L.; Zhao, Y.; Cao, R.; Li, L.; Cai, G.; Li, J.; Qi, X.; Chen, S.; Zhang, Z. Activity-based protein profiling reveals GSTO1 as the covalent target of piperlongumine and a promising target for combination therapy for cancer. Chem. Commun. 2019, 55, 4407-4410. [CrossRef] [PubMed]

13. Flores, N.; Ticona, J.C.; Bilbao-Ramos, P.; Dea-Ayuela, M.A.; Ruiz-Macedo, J.C.; Bazzocchi, I.L.; Bolás-Fernández, F.; Jiménez, I.A. An unprecedented chlorine-containing piperamide from Piper pseudoarboreum as potential leishmanicidal agent. Fitoterapia 2019, 134, 340-345. [CrossRef]

14. Galiana-Rosello, C.; Bilbao-Ramos, P.; Dea-Ayuela, M.A.; Rolón, M.; Vega, C.; Bolás-Fernández, F.; García-España, E.; Alfonso, J.; Coronel, C.; González-Rosende, M.E. In vivo and in vitro anti-leishmanial and trypanocidal studies of new N-benzene- and N-naphthalenesulfonamide derivatives. J. Med. Chem. 2013, 56, 8984-8998. [CrossRef] [PubMed]

15. Bilbao-Ramos, P.; Sifontes-Rodríguez, S.; Dea-Ayuela, M.A.; Bolás-Fernández, F. A fluorometric method for evaluation of pharmacological activity against intracellular Leishmania amastigotes. J. Microbiol. Methods 2012, 89, 8-11. [CrossRef] [PubMed]

16. Titus, R.G.; Marchand, M.; Boon, T.; Louis, J.A. A limiting dilution assay for quantifying Leishmania major in tissues of infected mice. Parasite Immunol. 1985, 7, 545-555. [CrossRef] [PubMed]

17. Rodrigues, R.F.; Charret, K.S.; Campos, M.C.; Amaral, V.; Echevarria, A.; dos Reis, C.; Canto-Cavalheiro, M.M.; Leon, L.L. The in vivo activity of 1,3,4-thiadiazolium-2-aminide compounds in the treatment of cutaneous and visceral leishmaniasis. J. Antimicrob. Chemother. 2012, 67, 182-190. [CrossRef]

18. Chen, J.J.; Huang, Y.C.; Chen, Y.C.; Huang, Y.T.; Wang, S.W.; Peng, C.Y.; Teng, C.M.; Chen, I.S. Cytotoxic amides from Piper sintenense. Planta Med. 2002, 68, 980-985. [CrossRef]

19. Duh, C.Y.; Wu, Y.C.; Wang, S.K. Cytotoxic pyridone alkaloids from Piper aborescens. Phytochemistry 1990, 29, 2689-2691. [CrossRef]

20. Navickiene, H.M.D.; Alécio, A.C.; Kato, M.J.; Bolzani, V.D.; Young, M.C.; Cavalheiro, A.J.; Furlan, M. Antifungal amides from Piper hispidum and Piper tuberculatum. Phytochemistry 2000, 55, 621-626. [CrossRef] 
21. Seeram, N.P.; Lewis, P.A.; Jacobs, H.; McLean, S.; Reynolds, W.F.; Tay, L.L.; Yu, M. 3,4-Epoxy-8,9dihydropiplartine. A new imide from Piper verrucosum. J. Nat. Prod. 1996, 59, 436-437. [CrossRef]

22. Araújo-Vilges, K.M.; Oliveira, S.V.; Couto, S.C.P.; Fokoue, H.H.; Romero, G.A.S.; Kato, M.J.; Romeiro, L.A.S.; Leite, J.R.S.A.; Kuckelhaus, S.A.S. Effect of piplartine and cinnamides on Leishmania amazonensis, Plasmodium falciparum and on peritoneal cells of Swiss mice. Pharm. Biol. 2017, 55, 1601-1607. [CrossRef] [PubMed]

23. Capello, T.M.; Martins, E.G.A.; Farias, C.F.; Figueiredo, C.R.; Matsuo, A.L.; Passero, L.F.; Oliveira-Silva, D.; Sartorelli, P.; Lago, J.H.G. Chemical composition and in vitro cytotoxic and antileishmanial activities of extract and essential oil from leaves of Piper cernuum. Nat. Prod. Commun. 2015, 10, 285-288. [CrossRef] [PubMed]

24. Bodiwala, H.S.; Singh, G.; Singh, R.; Dey, C.S.; Sharma, S.S.; Bhutani, K.K.; Singh, I.P. Antileishmanial amides and lignans from Piper cubeba and Piper retrofractum. J. Nat. Med. 2007, 61, 418-421. [CrossRef]

25. Moreira, F.L.; Riul, T.B.; Moreira, M.L.; Pilon, A.C.; Dias-Baruffi, M.; Araújo, M.S.S.; Lopes, N.P.; de Oliveira, A.R.M. Leishmanicidal effects of piperlongumine (piplartine) and its putative metabolites. Planta Med. 2018, 84, 1141-1148. [CrossRef]

26. Moreira, F.L.; Habenschus, M.D.; Barth, T.; Marques, L.M.; Pilon, A.C.; da Silva Bolzani, V.; Vessecchi, R.; Lopes, N.P.; de Oliveira, A.R. Metabolic profile and safety of piperlongumine. Sci. Rep. 2016, 6, 33646. [CrossRef]

27. Carneiro, G.; Aguiar, M.G.; Fernandes, A.P.; Ferreira, L.A. Drug delivery systems for the topical treatment of cutaneous leishmaniasis. Expert Opin. Drug Deliv. 2012, 9, 1083-1097. [CrossRef]

28. WHO. Leishmania. Treatment. Available online: https://www.who.int/health-topics/leishmaniasis\#tab=tab_3 (accessed on 8 April 2020).

29. Bilbao-Ramos, P.; Serrano, D.R.; Ruiz Saldaña, H.K.; Torrado, J.J.; Bolás-Fernández, F.; Dea-Ayuela, M.A. Evaluating the potential of ursolic acid as bioproduct for cutaneous and visceral leishmaniasis. Molecules 2020, 25, 1394. [CrossRef]

30. Liu, Z.; Shi, Z.; Lin, J.; Zhao, S.; Hao, M.; Xu, J.; Li, Y.; Zhao, Q.; Tao, L.; Diao, A. Piperlongumine-induced nuclear translocation of the FOXO3A transcription factor triggers BIM-mediated apoptosis in cancer cells. Biochem. Pharmacol. 2019, 163, 101-110. [CrossRef]

31. Rawat, L.; Hegde, H.; Hoti, S.; Nayak, V. Piperlongumine induces ROS mediated cell death and synergizes paclitaxel in human intestinal cancer cells. Biomed. Pharmacother. 2020, 128, 110243. [CrossRef] 